\title{
Ego e consciência em Jean-Paul Sartre
}

Henrique Mendes Gonçalves

\section{Resumo:}

Serão analisadas aqui as relações entre a primeira concepção sartreana de Ego e a consciência transcendental da fenomenologia, bem como a consequente delimitação de dois campos científicos distintos, que se configuram a partir dessas relações: o da descrição fenomenológica, que se ocupa da consciência transcendental purificada, e o da psicologia, que lida com a estrutura egológica transcendente. Tomaremos como referência bibliográfica fundamental o texto A transcendência do Ego: esboço de uma descrição fenomenológica, publicado em I936. Ao fim da análise, será apresentada uma série de possíveis problemas resultantes da concepção da consciência como único campo transcendental e imanente, condição de possibilidade para a redução fenomenológica.

Palavras-chave: Jean-Paul Sartre - fenomenologia - psicologia - Ego consciência 


\section{Introdução}

Em outubro de I933, durante uma conversa com Raymond Aron, então bolsista do Instituto Francês em Berlim, Jean-Paul Sartre se convenceu de que a fenomenologia de Edmund Husserl poderia lhe fornecer os instrumentos necessários para uma total reorientação dos temas enfocados pela investigação filosófica. Talvez fosse possível, por meio daquele modo radicalmente novo de conceber as relações entre mundo e consciência, produzir uma filosofia comprometida com o concreto, livre das relações de imanência que caracterizavam grande parte do pensamento francês da época, representado por Brunschvicg, Lalande e Meyerson (MOUTINHO, I995, p. 24).

A ideia de intencionalidade, central para a concepção husserliana da consciência, foi o que então pareceu ao jovem Sartre possibilitar essa ruptura com as dualidades do pensamento contemporâneo de cunho neokantiano e idealista, que opunha as representações e a vida interior a um mundo numênico, inacessível. O princípio que o conceito de intencionalidade nos apresenta, embora soe como algo próximo de um truísmo ao leitor incauto, é o de que toda consciência é consciência de algo. O grande ganho filosófico proporcionado por essa noção, se conjugada à redução fenomenológica ou epoché proposta por Husserl, é a abolição da invariável subjetividade a que a chamada "filosofia alimentar" conduzia toda a reflexão sobre o percebido: não se pode fazer uma ciência filosófica rigorosa que se apoie sobre as representações internalizadas pela consciência. A consciência passa a ser, então, na fenomenologia, não o receptáculo que internaliza tudo aquilo que é oferecido pela percepção, mas o único dado absoluto, imanente, índice de si mesmo, condição indispensável para o aparecimento do mundo fenomenologicamente reduzido. "A consciência e o mundo são dados de uma só vez: por essência exterior a ela, o mundo é, por essência, relativo a ela”, dirá Sartre (SARTRE, 2003b, p. 88).

Em seu breve ensaio Uma ideia fundamental da fenomenologia de Husserl: a intencionalidade, Sartre lembrará que "[...] Husserl vê na consciência um fato irredutível, que nenhuma imagem física é capaz de exprimir. A não ser, talvez, a imagem rápida e obscura da explosão" (SARTRE, 2003b, p. 88). Pode-se dizer que a consciência é, portanto, um constante movimento em direção ao mundo; o fluxo das consciências encadeadas é uma série ininterrupta de "explosões" no sentido da coisa que é o objeto intencional. Mas, para que a consciência desempenhe efetivamente o papel que a fenomenologia parece lhe querer atribuir, é necessário que algumas condições prévias se cumpram. A consciência, que deve ser portanto pura transparência, autoevidência absoluta desprovida de qualquer região opaca, tem de se ver livre de certas estruturas complexas que a filosofia 
idealista sempre lhe fez acompanhar. A mais recorrente delas é o Ego. Ora, a maior parte da tradição filosófica moderna se encontra edificada sobre uma ideia aparentemente incontestável: a da identidade entre consciência e Ego, que tem no cogito cartesiano sua síntese máxima e é condição epistemológica para a construção do saber filosófico. A proposta de Sartre enquanto fenomenólogo, em A transcendência do Ego, é precisamente a de extirpar o Ego do interior da consciência, devolvê-lo ao seu verdadeiro posto: o mundo transcendente, junto ali dos variados objetos que a consciência pode intencionar (e.g., esta cadeira, meu ódio, o Ego de Pierre ou a verdade matemática $2+2=4$ ).

A relação estabelecida entre consciência e Ego, como veremos, é portanto decisiva na delimitação dos campos de atuação tanto da descrição fenomenológica, quanto da psicologia, o que ajuda Sartre a superar o obstáculo do psicologismo que há muito tempo desafiava o inquérito filosófico. Devolvido o objeto transcendente Ego ao mundo, a psicologia pode finalmente se ocupar das questões que dizem respeito tão somente a ela: como se dá a formação da personalidade, o que são os estados psíquicos, quais as origens das psicastenias etc. Ao mesmo tempo, cabe à descrição fenomenológica a investigação dos temas pertinentes ao campo transcendental, que nada mais é do que a própria consciência transcendental. Sobre este campo purificado de qualquer estrutura egológica, onde todos os objetos transcendentais (i.e., aqueles que podem ser intencionados pela consciência transcendental) se dão, é possível erigir uma ciência filosófica rigorosa.

Talvez seja interessante realizar aqui ainda um breve excurso a fim de delimitar a peculiaridade semântica dos termos "transcendente" e "transcendental" no interior do léxico fenomenológico. A noção de transcendental remete imediatamente a Immanuel Kant, que foi por certo um interlocutor inevitável tanto para Husserl - especialmente ao longo do processo de elaboração de Ideias para uma fenomenologia pura e para uma filosofia fenomenológica, na qual uma fenomenologia transcendental se impõe à fenomenologia noética de seus trabalhos anteriores - quanto para Sartre, que inicia A transcendência do Ego com uma referência nominal ao fundador da filosofia crítica transcendental. É preciso alertar, no entanto, que se para Kant a transcendentalidade dizia respeito às condições de possibilidade para que o conhecimento humano ascendesse até o reino do metafísico, referindo-se portanto aos elementos lógico-categoriais imanentes e às formas da sensibilidade espaço-temporais enquanto dados subjetivos, para Husserl não seria possível sustentar uma oposição entre o mundo objetivo, ainda que fenomênico, e a dimensão da subjetividade. O transcendente e o transcendental devem, portanto, ser decifrados através de um dos conceitos-chave da filosofia husserliana: a intencionalidade. 
Ao menos tendo-se em vista o que nos informa a interpretação sartreana da fenomenologia de Husserl e o momento histórico em que ela se inscreve, a consciência pura é o único domínio propriamente imanente, autoevidente e, portanto, transcendental. Em oposição a essa consciência destituída de qualquer estrutura interna apriorística que fizesse às vezes de campo transcendental, surgem os objetos do mundo fenomenologicamente reduzido: os fenômenos, para insistir na intercessão entre o vocabulário técnico de Kant e Husserl. Esses objetos, que correspondem a tudo aquilo que a consciência pode intencionar - real ou imaginário, ideal ou extenso etc. -, constituem para a fenomenologia o domínio propriamente transcendente; i.e., aquilo que existirá por meio da transcendentalidade da consciência pura. Mantendo em vista as peculiaridades semânticas desses dois termos no interior da filosofia fenomenológica, podemos agora partir para uma análise da estrutura e da argumentação de A transcendência do Ego.

\section{O Ego formal}

Antes de passar a uma análise das relações que a fenomenologia sartreana estabelece entre consciência e Ego, é preciso delimitar cuidadosamente o estatuto de ambos no interior do texto. Para tanto, será brevemente reconstruído o percurso argumentativo que nega a transcendentalidade do Ego, afirmando ao mesmo tempo sua transcendência como objeto intencional. A primeira parte do ensaio A transcendência do Ego tem caráter negativo, contrapõe-se às teorias vigentes a respeito da constituição do Ego e de sua relação com a consciência humana, mas não nos apresenta ainda aquilo que será a explicação fenomenológica sartreana para o problema. Para situar o problema filosófico que será desenvolvido ao longo do ensaio - o da existência do Ego e de suas relações com a consciência -, Sartre recorrerá a Kant, que, por meio da filosofia crítica, desenvolveu ideias que lançariam os fundamentos tanto de uma vertente idealista da filosofia, então hegemônica na França, quanto da fenomenologia de Husserl.

Para Sartre, ao afirmar que "o Eu penso deve poder acompanhar todas nossas representações", Kant coloca o problema da existência de direito do Eu penso (SARTRE, 2003a, p. 94). Isto é, não decorre da tese kantiana que uma consciência do Ego acompanhe sempre e necessariamente todas as representações. De um modo geral, no entanto, os filósofos do neokantismo francês parecem realizar de fato aquilo que para Kant existe como uma potencialidade, uma existência de direito do Ego como acompanhante de todas as representações. Tal equívoco conduz inevitavelmente à constituição de uma estrutura egoica 
formal, e Sartre se ocupará de desfazer a falácia no item A da primeira parte de seu ensaio. A presença de um Ego transcendental (e não transcendente, o que significa que ele é condição de possibilidade para qualquer conhecimento) que unifica as consciências cria um ponto opaco inacessível à própria consciência. Embora ele próprio seja condição para o conhecimento, o Ego transcendental, se existisse, não poderia ser conhecido.

Curiosamente, no entanto, o próprio Husserl passou a admitir a partir de Ideias a existência de uma espécie de Ego formal. Que a tradição idealista aceite a existência do Ego formal, dada a natureza de seu projeto filosófico, é compreensível. Semelhante concepção, entretanto, não tem espaço no interior da fenomenologia enquanto ciência descritiva dos fatos; na realidade, sua aceitação implicaria a destruição de todas as conquistas até então realizadas pelo projeto fenomenológico, uma vez que ameaçaria a translucidez e a autoevidência da consciência. A crítica sartreana à concessão de Husserl ao idealismo recorrerá, portanto, a uma teoria anterior do próprio filósofo alemão, a saber, a da consciência íntima do tempo:

É a própria consciência que se unifica concretamente por meio de um jogo de intencionalidades "transversais", que são retenções concretas e reais de consciências passadas. Assim, a consciência remete-se perpetuamente a ela mesma, quem diz "uma consciência" diz toda a consciência e esta propriedade singular pertence à própria consciência, quaisquer que sejam suas relações com o Eu [Ego] (SARTRE, 2003a, p. 97).

Assim, à questão de se o Eu penso kantiano é o operador da síntese das consciências, Sartre dá uma resposta negativa: a consciência transcendental se autounifica e não tem necessidade de qualquer tipo de estrutura interna, é sua unidade prévia que permite a formulação do Eu penso, e ela antecede a existência de qualquer tipo de Ego. Vê-se logo, portanto, que não há necessidade de se aceitar a existência da estrutura egológica formal. Mas, para além disso, sua aceitação seria prejudicial. Aceitar a existência do Ego formal comprometeria o caráter não substancial que, a princípio, admitiu-se ser o da consciência. Para a consciência transcendental, o ser e o aparecer devem se igualar, i.e., ela deve ser passível de ser consciência de si mesma. Concluindo sua crítica ao Ego formal husserliano, Sartre afirma o seguinte:

[...] Se este Eu [Ego] é uma estrutura necessária da consciência, este Eu opaco é elevado, pelo mesmo movimento, à ordem do absoluto. Ei-nos, pois, na presença de uma mônada. Esta é, infelizmente, a nova orientação do pensamento de 
Husserl (veja as Meditações Cartesianas). A consciência tornou-se pesada, ela perdeu a característica que fazia dela o existente absoluto porforça do inexistente. Ela é pesada e mensurável. Todos os resultados da fenomenologia ameaçam arruinar-se se o Eu não for, a mesmo título que o mundo, um existente relativo, isto é, um objeto para a consciência (SARTRE, 2003a, p. 98; grifo nosso).

Claro como está que o Ego não pode se localizar formalmente no interior da consciência, cabe uma série de perguntas, da qual a mais importante e central parece ser: como e onde surge, então, o Ego? Sartre admite que é mediante o cogito que se dá sua aparição, mas matizará a validade do movimento argumentativo cartesiano através da introdução das noções de consciência reflexiva e irrefletida. A formulação do cogito como "penso, logo existo" é equívoca na medida em que assume previamente uma identidade entre o Ego e a consciência.

Ocorre que, na maior parte do tempo, enquanto a consciência simplesmente intenciona os objetos transcendentes do mundo, o Ego se ausenta. Se corro atrás de um bonde para apanhá-lo, por exemplo, o que há é unicamente a consciência do "bonde-adiante-prestes-a-ser-alcançado" (SARTRE, 2003a, p. IO2). O Ego apenas surge efetivamente em uma segunda instância, na ocasião em que a consciência se debruça sobre si mesma: tenho, assim, consciência de ter consciência; sou eu quem corre para apanhar o bonde, pode-se então aceitar a presença do Ego, embora não como unificador, mas como depreensão possível da unidade intrínseca do fluxo de consciências. A esse tipo de consciência Sartre dá o nome de "reflexiva", em oposição à "irrefletida", na qual a consciência intenciona outros objetos que não ela mesma. Esses são conceitos fundamentais para a compreensão de como se configura aquilo que se chama corriqueiramente de identidade, processo cuja análise já se encontra sob o domínio científico da psicologia e que será abordado mais adiante, mas não sem que antes nos detenhamos brevemente sobre a última refutação de Sartre a uma das teorias egológicas tradicionais: a da presença material do Ego, defendida pela tradição moralista francesa e que tem em La Rochefoucauld seu mais notório representante. Um sutil paralelo pode ser traçado entre tal concepção das estruturas psíquicas e a noção de inconsciente na psicanálise freudiana, que então aportava ainda timidamente na França.

\section{O Ego material}

A teoria psicológica de um Ego materialmente presente na consciência é a última a ser refutada. Nessa tradição, iniciada em larga medida pela obra do 
aforista francês La Rochefoucauld, o Ego nos é apresentado como uma estrutura dissimulada que sempre age em proveito próprio, ainda que o indivíduo não se dê conta disso. As eventuais semelhanças com o conceito freudiano de inconsciente fazem com que a crítica sartreana possa se estender, em certa medida, também à doutrina psicanalítica. Para Sartre, o erro dos moralistas do Ego dissimulado consiste em uma mistura indevida do conceito de consciência reflexiva e irrefletida. A consciência irrefletida precede sempre a reflexiva, pois seria absurdo conceber que o estado natural da consciência fosse a reflexão sobre si mesma: o homem estaria assim incapacitado até mesmo de lidar com suas representações, de interagir com o mundo.

Os moralistas concebem um tipo de consciência mista: há por um lado uma consciência reflexiva constante, incessante, que age, no entanto, dissimuladamente e travestida de consciência irrefletida. Portanto, ao ver Pierre em apuros, por exemplo, eu seria impelido a ajudá-lo, não por altruísmo ou pela urgência da situação, que o apresenta como alguém que deve ser socorrido, mas pela necessidade de afirmar meus valores ou pela expectativa de ser recompensado pelo feito. Tal concepção está absolutamente equivocada, dirá Sartre: ao ver Pierre em apuros, há tão só a consciência de "Pierre-que-deve-ser-socorrido", uma vez que opero no âmbito irrefletido. Qualquer tipo de hesitação ou decisão que envolva a relação entre meu Ego e Pierre - posso me expor ao risco na tentativa de socorrê-lo, posso ter Pierre como inimigo pessoal -, só se dará em um segundo grau, o da consciência reflexiva, que é precisamente o instante do surgimento do Ego. "Antes de serem envenenados', meus desejos foram puros: foi o ponto de vista que tomei sobre eles que os envenenou", dirá Sartre (2003a, p. IO7).

\section{A constituição do Ego}

Já concluímos pela invalidade da identificação entre Ego e consciência, tomada pela tradição como pressuposto para o desenvolvimento de uma filosofia idealista. Vimos que, para Sartre, a fenomenologia deve se ocupar da consciência enquanto único campo transcendental, imanente, absoluto e, portanto, não passível de redução. Vimos ainda que uma tal concepção não admite a presença de qualquer espécie de Ego como operador de sínteses de consciências ou realizador de alguma outra função a priori. O Ego, portanto, não mais surgirá como um resíduo do cogito, mas sua constituição deverá ser iniciada pelo processo reflexivo da consciência: o intencionar-se a si mesma, intencionar à sua unidade e individualidade enquanto diferença em relação à 
consciência de outrem. Mas esse Ego que nasce assim ainda nos parece muito distante daquele objeto de estudo da psicologia; parece-nos unidimensional, sem profundidade. Sartre tratará de lhe conferir identidade a partir da segunda parte de seu texto, "A constituição do Ego", que compõe a seção propriamente positiva da obra. O comentarista da obra sartreana Luiz Damon Santos Moutinho afirmará:

Afastado o Eu [Ego] do campo da imanência, tornado transcendente, ele parece agora ganhar um papel que lhe foi recusado quando este parecia possível. De fato, é incompreensível que se fale em um Ego transcendente como realizador de síntese. A solução desse problema liga-se à última de nossas questões indicadas acima, a da constituição do Ego (MOUTINHO, I995, p. 4I).

Trata-se aqui de conferir a identidade ao Ego. Para Sartre, ela é preenchida pela síntese dos estados psíquicos (e.g., o ódio, o amor etc.), que apresentam uma ligação direta com o polo passivo ou moi do Ego; das ações (e.g., o pensar, o duvidar etc.), que são constituintes de seu polo ativo ou je; e, finalmente, das qualidades (e.g., sou raivoso, sou amoroso etc.), que são considerações sobre o Ego derivadas da atuação da consciência reflexiva sobre os estados (se sinto ódio frequentemente, serei raivoso; se amor, amoroso etc.). Os estados, ações e qualidades são transcendentes que se encontram colocados no mesmo nível do próprio Ego: o do mundo. Eles compõem o Ego, mas devem ser tomados também em sua individualidade objetiva, como as notas musicais que compõem uma sinfonia. Ao mesmo tempo, no entanto, o próprio estado ou a ação transcendente é uma síntese; uma síntese de diversos momentos da consciência. Se sinto, por exemplo, uma grande repulsa por Pierre em determinado momento, essa repulsa - como objeto intencional reduzido pela epoché - é um fato. Se a repulsa persiste, entretanto, a cada vez que eu o encontre, posso ou não considerar que eu sinta ódio por Pierre, mas essa seria já uma operação sintética, de segundo grau. Nesse sentido, o estado (no caso, o ódio) não é nunca um dado absoluto, certo; e a mesma afirmação pode ser estendida às ações e às qualidades, sendo estas últimas nada mais do que simplesmente a atribuição da qualidade de pretensos estados sucessivos ao Ego (e.g., o fato de eu odiar não apenas Pierre, mas também muitas outras pessoas, pode fazer com que eu classifique a mim mesmo como uma pessoa raivosa). "Não se necessita de mais para que os direitos de reflexão estejam singularmente limitados: é certo que Pierre me repugna, mas é e sempre será duvidoso que eu o odeie" (SARTRE, 2003a, p. IOg), dirá Sartre. Disso se depreendem dois fatos: primeiramente, o Ego passa a ser, portanto, instável, 
difícil de perscrutar; em segundo lugar, o meu Ego é para mim tão estranho quanto o de outrem. A psicologia e a fenomenologia do Ego são antinômicas. Sartre procurou mostrar que a psicologia dos estados mentais nunca deixará de ser hipotética, o que significa que aquilo que se chama de ódio ou amor diz respeito a uma mera questão de interpretação.

O Ego é o objeto transcendente que realiza a síntese permanente do psíquico. A estrutura egoica é então um polo de ações, estados e qualidades. A isso se opõe o vazio absoluto da consciência intencional e transcendental: esta não acarreta qualquer tipo de determinação, é sempre tão somente o transcender-se a si mesma, o projetar-se no mundo através da intencionalidade e, também, a autoevidência absoluta de um transcendental. Estão assim constituídos dois campos científicos próprios: primeiramente, o da descrição fenomenológica, que é o campo de investigação da consciência transcendental propriamente dita; e, em segundo lugar, o da psicologia, que é o de uma egologia ou análise do Ego enquanto objeto transcendente. Sartre parece ter concluído sua tarefa de fundamentação da psicologia, adequando-a ao projeto científico fenomenológico de Husserl, embora tenha divergido de seu próprio mestre no que diz respeito a um dos pontos fundamentais de tal questão: o estatuto do Ego.

\section{v. Relações entre Ego e consciência}

Mas essa partilha entre as ciências da psicologia e da fenomenologia produz certas consequências inesperadas e não anunciadas, cuja menção só é feita mais ao final do texto. Uma delas é a já observada espontaneidade absoluta da consciência: livre de qualquer determinação prévia, ela é possibilidade infinita, pode produzir qualquer estado ou ação. É por isso que frequentemente somos levados a nos perguntar: "Mas eu? Como eu fui capaz de fazer algo assim?". O Ego, por sua vez, apresenta uma pseudoespontaneidade, fruto daquela antiga concepção que o coloca não como produto, mas como produtor da síntese das consciências. De modo distinto, a espontaneidade da consciência é absoluta; nada pode agir sobre ela pois é causa de si mesma.

É por isso que a função do Ego, por consequência, parece ser a de mascarar essa espontaneidade "monstruosa" da consciência, como Sartre a qualifica. Ele é um porto seguro ao qual se pode recorrer e se recorre, o tempo todo, a fim de que sejam mitigados os ímpetos quase incontroláveis da consciência transcendental. Essa articulação é o que pode dar origem a toda uma leitura ética dos primeiros textos de Sartre, que evidentemente será mais bem de- 
senvolvida apenas em suas obras tardias, por não haver ainda espaço, nesse momento de fundamentação, para uma reflexão ulterior. A noção do homem fadado à liberdade, tão cara ao projeto filosófico sartreano em toda a sua extensão, e mesmo os fundamentos da célebre máxima existencialista - "A existência precede a essência" - já se encontram prenunciadas nessa passagem do texto, embora de uma maneira ainda muito embrionária e pouco articulada.

\section{Problemas da consciência transcendental}

A transcendência do Ego fornece importantes subsídios para a reflexão acerca das conquistas realizadas pelo trabalho de Husserl, abrindo caminho para um novo e produtivo campo de investigação filosófica, mas há uma série de problemas decorrentes do papel que Sartre assinala à fenomenologia transcendental que não são suficientemente abordados no texto. Porque foi devolvido ao seu posto no mundo, o Ego de Pierre é acessível a mim tanto quanto a cor deste tinteiro ou qualquer outro objeto intencional. No entanto, sua consciência não o é. Ao menos neste primeiro momento da filosofia sartreana, a consciência do outro segue sendo absolutamente inalcançável. Ela é, tanto quanto a minha, imanente e o único campo isento da epoché, já que é ela mesma a própria condição para a redução. É possível dizer, portanto, que embora seja superada uma determinada série de aporias resultantes da concepção idealista de um Ego-calabouço amalgamado à consciência, a pré- ontologia a que o campo transcendental parece nos dar acesso não é capaz de resolver outras questões, resultantes da condição de absoluta imanência que confere à própria consciência transcendental.

Pode-se propor, a título de exemplo, o antigo problema epistemológico dos qualia, ou das diferentes percepções das propriedades de um objeto. Ao observar a cor deste tinteiro, posso percebê-la como azul-marinho ou como o matiz que ao longo de toda a minha vida tenho associado ao nome "azul- marinho" - impossível de se descrever em palavras, dado o caráter absolutamente elementar das cores. Pierre, no entanto, pode talvez perceber um matiz diferente do que eu percebo ao observar o tinteiro e pode ainda perceber esse mesmo matiz que vê agora, por exemplo, na cor de fundo da bandeira britânica ou no azul da água em alto-mar. Nesse caso, Pierre e eu chamaríamos percepções distintas pelo mesmo nome e isso ocorreria unicamente por conta de sua recorrência sempre nos mesmos objetos, de modo que eu poderia dizer: "Pierre, observe como é bela essa tinta azul-marinho" e receber uma resposta positiva, ainda que percebêssemos efetivamente cores distintas. 
Enunciado de tal forma, o problema pode parecer se distanciar da temática central da reflexão sartreana e, especificamente, daquela que nos é apresentada em A transcendência do Ego. No entanto, há uma série de objeções paralelas, estruturalmente análogas e colocadas pelo próprio Sartre no texto em questão e em outros, posteriores e anteriores, objeções que podem e devem ser invocadas quando se trata das divergências entre as características dos objetos intencionais de cada consciência em particular. Tomemos por exemplo a refutação da teoria dos moralistas franceses, já analisada anteriormente, teoria que nos remete ao pequeno ensaio Uma ideia fundamental da fenomenologia de Husserl: a intencionalidade. O texto foi publicado em 1939, mas estima-se que sua elaboração deve ter se dado por volta do ano de I934, o que faz com que se estabeleça uma espécie de relação de continuidade entre ele e A transcendência do Ego, de 1936. De fato, muito do que é apresentado naquele primeiro ensaio de forma sucinta e ainda pouco elaborada se desenvolve de maneira mais profunda no texto posterior. Um desses tópicos permite ao leitor vislumbrar uma dimensão secundária de A transcendência do Ego: a das valorações ético-estéticas.

Tomam-se aqui os domínios da Ética e da Estética de maneira binomial porque, no mundo fenomenologicamente reduzido dos objetos intencionais da consciência, a aparência e a valoração surgem de maneira concomitante. Encontrando-me ainda na primeira instância de operação da consciência, a irreflexão e a não consciência de si ou do Ego, sempre que confrontado com uma determinada situação, minha valoração e os estados psíquicos (ódio, amor, compaixão etc.) que dela decorrem só poderão advir da própria espontaneidade irrefreável da consciência. Mais uma vez, o que a situação de perigo em que se encontra Pierre me informa é apenas que ele deve ser socorrido, e no plano irrefletido não há nada mais do que essa consciência absoluta de um homem em perigo. Não se trata aqui de um processo psíquico complexo pelo qual eu internalizo os dados dos sentidos e, por meio de um confronto com minhas memórias e meus afetos relativos a Pierre, produzo uma resposta adequada. O confronto só poderia se dar em uma segunda instância, de maneira refletida, a partir do momento em que o Ego fosse constituído pela consciência reflexiva e distorcesse a primeira reação, pura e incontaminada, orientada pelo próprio objeto intencional. Nem sempre é possível que o processo se concretize: talvez isso explique por que, diante de uma situação de perigo, por vezes nos vejamos dispostos a proteger até mesmo aqueles que tomamos por inimigos.

Eis que essas famosas reações "subjetivas" - ódio, amor, temor, simpatia -, que boiavam na malcheirosa salmoura do Espírito, de repente se desvencilham dele: 
são apenas maneiras de descobrir o mundo. São as coisas que subitamente se desvendam para nós como odiáveis, simpáticas, horríveis, amáveis. Constitui uma propriedade dessa máscara japonesa ser terrível - uma inesgotável e irredutível propriedade que constitui sua própria natureza - e não a soma de nossas reações subjetivas a um pedaço de madeira esculpida. Husserl reinstalou o horror e o encanto nas coisas. Ele nos restituiu o mundo dos artistas e dos profetas: assustador, hostil, perigoso, com portos seguros de dádiva e de amor (SARTRE, 2003b, p. 89).

Seguindo esse raciocínio, constitui ainda uma propriedade da mulher que se ama ser amável; da peça musical que se detesta, detestável; do alimento que se come com gosto, saboroso. Mas se os valores antes tidos como subjetivos se encontram inscritos na própria natureza do objeto, ocupando, portanto, agora, o polo da objetividade, como é possível que pessoas diferentes tenham reações distintas ante o mesmo objeto? A aporia não se resolve nem mesmo ao final da leitura de $A$ transcendência do Ego, embora seja possível arriscar uma explicação coerente com as teses sartreanas, que, no entanto, não parece de todo satisfatória. Absolutamente independentes de qualquer estrutura egoica transcendental, os valores informados pelo objeto intencionado, conjugado de maneira inseparável à consciência pela fórmula máxima da intencionalidade, têm de advir da pura espontaneidade e contingência da consciência. Isso quer dizer que é a consciência pura, independentemente de uma personalidade constituída, gostos ou preferências, que oferece a valoração que antes se acreditava ser o produto final de um processo de internalização dos dados dos sentidos.

Embora Sartre não desenvolva todas as consequências dessas teses, uma série de problemas éticos e estéticos se prenuncia: como é possível assumir responsabilidade sobre algo que escapa ao meu domínio de ação, sobre algo que brota espontaneamente e de maneira contingente, para a minha consciência, como parte da natureza do objeto intencionado? Como é possível justificar o gosto e as preferências estéticas, se não podemos compreender como a consciência espontânea conduz o processo de apreciação?

Ora, não se pode constituir uma ciência do que é absolutamente contingente e, por isso, o aspecto ativo da consciência, como produtora de valorações e de estados psíquicos, é uma espécie de ponto cego no interior da teoria egológica de Sartre. Mas, além disso, é evidente que essa explicação não nos livra do risco do solipsismo, que persiste ao longo de todo o ensaio. Não se trata aqui do solipsismo de cunho cartesiano, ameaçado pelo domínio absoluto do Gênio Maligno sobre tudo aquilo o que não é sujeito, mas antes de 
uma espécie de solipsismo bem particular à fenomenologia de Sartre: aquele que se relaciona com a impossibilidade de se averiguar a existência de outra consciência que não aquela a que tenho acesso, anterior até mesmo a qualquer discussão acerca da existência de um sujeito constituído ou constituinte.

Mais uma vez, como ignorar a objeção que surge imediatamente na mente de cada leitor: a de que é difícil aceitar a existência de qualidades do objeto quando cada consciência parece apreendê-las de maneira tão discrepante? Em sua tentativa de superar a epistemologia, o único terreno "conhecido da filosofia francesa", Sartre parece por vezes simplesmente descartar automaticamente alguns dos problemas que persistiram, embora pudessem ser e fossem àquela altura tradicionalmente associados à "malcheirosa salmoura do Espírito" (SARTRE, 2003b, p. 89), considerando-os talvez problemas decorrentes, como os demais, da dualidade idealista Ego-consciência. Talvez seja necessário, porém, problematizar também a noção de consciência enquanto imanente, absolutamente fundamental para o ponto de vista desenvolvido em A transcendência do Ego.

A concepção sartreana da consciência e de seu respectivo domínio científico (i.e., a fenomenologia) parece limitar o campo do evidente, no interior do mundo fenomenologicamente reduzido, às velhas tautologias. Não posso conhecer meu ódio de maneira mais direta do que um terceiro o conhecerá, já que esse estado se constitui sobre a interpretação - minha ou de outrem, isto é indiferente - e sobre as relações que se estabelecem entre várias vivências independentes e autônomas, cuja origem comum é apenas o contingente absoluto, o vazio inexplicável da consciência.

Levando-se em conta a contingência do mundo dado, parece necessário que só exista a reflexão pura sob a forma descritiva e não preditiva. A fenomenologia deve se abster, portanto, de buscar se apresentar como uma ciência do que pode ser antecipado, como a física ou a química, uma vez que seu objeto pode apenas ser pensado sob a égide da absoluta correspondência entre objeto intencional imediatamente dado e a consciência transcendental, comprimido, portanto, como uma espécie de mônada temporal.

Pode-se entender, a partir dessas constatações, a afirmação do comentador belga Vincent de Coorebyter de que uma interpretação recorrente de A transcendência do Ego no mundo anglo-saxão busca por vezes aproximar o texto de um tradição "[...] desconstrucionista, herdada antes de Hume do que de Heidegger" (COOREBYTER, 2003, p. 7). De fato, a noção apresentada por Sartre de contingência, presente não apenas em seus textos filosóficos, como também no romance $A$ náusea, parece aproximá-lo de algumas das ideias centrais da tradição antimetafísica inaugurada pelo filósofo escocês. 
No que diz respeito ao acesso às consciências passadas, cabe semelhante objeção: considerando-se seu caráter constituído, produzido pela intencionalidade presente da memória, o passado tem um estatuto ontológico semelhante àquele dos demais objetos intencionais. "Cada instante de nossa vida consciente nos revela uma criação ex nihilo" (SARTRE, 2003a, p. I27), afirma Sartre em uma passagem de A transcendência do Ego.

Isso dificulta a aceitação dos argumentos contrários ao Ego formal de Husserl; a saber, os de que a consciência se autounifica mediante um "jogo de intencionalidades transversais, que são retenções concretas e reais das consciências passadas". Ora, se o passado é relegado ao campo duvidoso da reflexão impura, uma vez que erigido sobre aquilo que é constituído, e não constituinte, como se poderia afirmar a unidade do fluxo da consciência recorrendo-se às intencionalidades transversais - i.e., à memória -, que apresentam um estatuto ontológico semelhante ao de qualquer outro fenômeno, de qualquer outro objeto intencional transcendente? De modo semelhante, o âmbito da ação, enquanto categoria abrangente para os fenômenos psíquicos que têm o tempo como condição de possibilidade para a sua efetivação, é dessa maneira inserido no domínio da impureza.

É evidente que a fenomenologia teve de se apoiar sobre algum solo seguro em sua tentativa de construir uma filosofia rigorosamente científica, e foi a consciência que desempenhou tal papel. Dessa forma, venceram-se uma série de obstáculos postos pela teoria idealista, especialmente no que diz respeito à possibilidade de construir uma filosofia que fosse além da subjetividade, que se projetasse no próprio mundo. Mas Sartre mais tarde perceberá as limitações que as concepções fenomenológicas husserlianas impõem a seu projeto inicial, o de levar a filosofia até a concretude do mundo e de realizar uma filosofia de situações, tendo de buscá-lo em uma espécie de ontologia existencialista (cujo ponto de maturidade se encontra em $O$ ser e o nada), já agora mais receptiva às influências de Heidegger, embora sem se comprometer com sua obra com a mesma fidelidade e entusiasmo que o levaram a aderir ao projeto da fenomenologia proposto por Husserl.

\section{viI. Conclusão}

O tema da dissolução do Ego e suas variantes monopolizou o debate nos mais diversos campos das ciências humanas ao longo de grande parte do século XX. Pode-se encontrá-lo claramente enunciado no tópico foucaultiano da morte do homem ou na resposta dada pelos teóricos e críticos literários à poesia 
antilírica e à narrativa despersonalizada dos autores do nouveau roman. Nesse sentido, o ensaio A transcendência do Ego, uma espécie de precursor da temática do fim da subjetividade, foi visto por muitos autores - alguns deles declaradamente antissartreanos, avessos tanto à fenomenologia tradicional quanto às várias vertentes do existencialismo - como um marco inaugural, um divisor de águas. Talvez residam aí sua atualidade e relevância, bem como o interesse em resgatar um texto que é por vezes interpretado, erroneamente, como uma mera preparação para o desenvolvimento dos tópicos verdadeiramente relevantes trabalhados na grande obra de maturidade intelectual de Jean-Paul Sartre, O ser e o nada (COOREBYTER, 2003, p. 7).

A leitura de A transcendência do Ego revela que a filiação de Sartre à fenomenologia husserliana apresenta características que, muitas vezes, parecem distingui-lo de outros fenomenólogos, adeptos de uma postura mais ortodoxa em relação à obra do Husserl. Uma forte nuance realista perpassa toda a primeira etapa de sua produção filosófica, o que é confirmado pelo próprio autor em entrevista concedida ao periódico britânico New Left Review e compilada no nono volume da série Situações: "Minha preocupação na época [...] era a de conferir um fundo filosófico ao realismo. [...] A questão era: como oferecer ao mesmo tempo ao homem sua autonomia e sua realidade entre os objetos reais, evitando o idealismo e sem cair em um materialismo mecanicista?" (SARTRE, I972, p. IO4).

A busca de Husserl pelas estruturas essenciais da experiência parece ser significativamente distinta do compromisso que a filosofia de Sartre assume com o mundo concreto. A afirmação do pretenso cunho realista da fenomenologia por parte de Aron parece ter facilitado a conversão do jovem Sartre. Um distanciamento deveria, contudo, ocorrer inevitavelmente, assim que o autor se convencesse da insuficiência dos postulados da fenomenologia pura ao lidar com alguns dos temas centrais de suas principais inquirições e interesses filosóficos.

A ruptura com o método fenomenológico husserliano já se faz evidente em um emblemático texto, publicado em I939 (logo, apenas três anos após A transcendência do Ego), o Esboço para uma teoria das emoções. Nele, Sartre recorre à psicologia não mais como um domínio meramente constituído pela fenomenologia transcendental, a exemplo das demais ciências, mas reconhece e valoriza também o caráter constituinte da dimensão puramente psíquica. Foge do escopo deste artigo, no entanto, uma análise pormenorizada da mudança de perspectiva que tal obra promove no processo de maturação do pensamento sartreano. $\mathrm{O}$ que se tentou fazer aqui foi uma breve apresentação dos motivos que levaram o autor a se interessar pelas novas possibilidades abertas 
à investigação filosófica a partir da então nascente ciência da fenomenologia - a saber: a possibilidade da dissolução da dualidade sujeito-objeto defendida pela filosofia idealista, bem como o vínculo que dela deveria decorrer entre atividade filosófica e mundo concreto. Tentou-se ainda mostrar que da conjugação desses objetivos aos pressupostos da fenomenologia derivam certas aporias, problemas filosóficos de difícil solução que certamente contribuíram para que o autor se visse inclinado a se distanciar gradativamente da fenomenologia husserliana, buscando, já sob a influência de Heidegger, traçar um novo caminho de investigação filosófica, que culminaria em I943 com a publicação de $O$ ser e o nada.

\section{Referências bibliográficas}

COOREBYTER, V. Introduction. In: La transcendence de l'Ego et autres textes phénoménologiques. Paris: J. Vrin, 2003.

HUSSERL, E. Ideen zu einer reinen Phänomenologie und phänomenologischen Philosophie I. Hua III. Haag: Martinus Nijhoff, I950. . Logische Untersuchungen. Hua XIX. Haag: Martinus Nijhoff, I984.

MOUTINHO, L. D. Sartre: psicologia e fenomenologia. São Paulo: Brasiliense, I995.

SARTRE, J.-P. La transcendance de l'Ego. In: La transcendance de l'Ego et autres textes phénoménologiques. Paris: Vrin, 2003 a. . Sur moi-même. In: Situations IX. Paris: Gallimard, I972. . Une idée fondamentale de la phénoménologie de Husserl: l'intentionnalité. In: La transcendance de l'Ego et autres textes phénoménologiques. Paris: Vrin, 2003b.

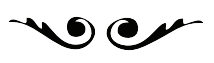

Henrique Mendes Gonçalves - Graduando em Filosofia pela FFLGH - Universidade de São Paulo. henriquemendesg@hotmail.com 